\title{
Optimization of Agrobacterium-mediated transformation procedure for grapevine 'Kyoho' with carrot antifreeze protein gene
}

\author{
Hye Young Shin - Gi Hoon Kim - Sang Jae Kang · Jeung-Sul Han - Cheol Choi
}

Received: 22 August 2017 / Revised: 14 October 2017 / Accepted: 20 October 2017

(c) Korean Society for Plant Biotechnology

\begin{abstract}
We report an Agrobacterium-mediated transformation procedure optimized for 'Kyoho' that is a major table grapevine cultivar in Korea, and its transgenic plants with antifreeze protein gene of carrot $(D c A F P)$. The full length of $D c A F P$ coding region in accordance with the previous report was isolated from young leaves of carrot and recombined into a plant transformation vector. Ethylene inhibitors such as silver nitrate and aminoethoxyvinylglycin (AVG) supplemented in a co-cultivation medium distinctly increased frequency of shoot regeneration when explants were sub-cultured in a selection medium: particularly ten-fold higher in treatment with $0.1 \mathrm{mg} / \mathrm{L}$ AVG than one without ethylene inhibitor. Among various antibiotics and their concentrations, the combination of 150 $\mathrm{mg} / \mathrm{L}$ cefotaxime plus $150 \mathrm{mg} / \mathrm{L} \mathrm{Clavamox}^{\mathrm{TM}}$ was selected for elimination of Agrobacterium cells in addition to minimization of adverse effect on shoot regeneration, while $50 \mathrm{mg} / \mathrm{L}$ kanamycin monosulfate effectively suppressed regeneration of nontransgenic shoots. Applying the elucidated culture condition, we finally obtained a total of 5 transgenic 'Kyoho' plantlets with $D c A F P$, of which integration with the grapevine genome and transcription was confirmed by nucleic acid analyses.
\end{abstract}

H. Y. Shin · G. H. Kim · J.-S. Han · C. Choi $(\bowtie)$

Department of Horticultural Science, College of Agriculture \& Life Sciences, Kyungpook National University, Daegu 41566, Republic of Korea

e-mail: cc31@knu.ac.kr

\section{S. J. Kang}

School of Applied Life Science, College of Agriculture \& Life Sciences, Kyungpook National University, Daegu 41566, Republic of Korea

\section{J.-S. Han}

Department of Ecological Environment, College of Ecology \& Environmental Science, Kyungpook National University, Sangju 37224, Republic of Korea

J.-S. Han · C. Choi

Institute of Agricultural Science \& Technology, Kyungpook

National University, Daegu 41566, Republic of Korea
Keywords Genotype, Agrobacterium overgrowth, Antibiotics concentration, Vitis vinifera, Cold-tolerance

\section{Introduction}

Grapevine (Vitis spp.) is considered to be one of the major fruit crops in the world based on hectares cultivated and economic value (Torregrosa et al. 2015). Recently, various approaches to improve economically important characteristics in this crop has comprised genetic engineering, by which transgenic grapevines have been obtained in a stream (Iocco et al. 2001; Kim et al. 2013; Li et al. 2006). However, few efforts were involved in developing the event with enhanced cold-tolerance that is a primary characteristics in grapevine cultivation (Jin et al. 2009; Sun et al. 2016). Coldness like other abiotic stresses has adverse effects on the growth and development of grapevine plants (Wang and Nick 2017). A table grapevine 'Kyoho' is generally less cold-tolerant than the American grapevine cultivars derived from an interspecific hybridization (Sun et al. 2016), resulting in being cultivated in a greenhouse or buried during winter season in Korea. The former leads to increase cost of production while the latter make the scions be vulnerable to soil-borne diseases, especially to crown gall.

Since the characterization of antifreeze protein (AFP) from Antarctic fishes (DeVries et al. 1970), many other AFPs were isolated from Arctic fishes, insects, and carrot at last (Jang et al. 1999; Meyer et al. 1999; Worrall et al. 1998). Functional studies on the $A F P$ of carrot $(D c A F P)$ further revealed the inhibitory effects of its protein on ice growth and recrystallization, which suggests the potential of this gene for crop improvement. Although genetic transformation technology encourages to express $D c A F P$ for cold-tolerance in grapevines, each grapevine genotype crucially demands a deliberate genetic transformation system merged with an efficient in vitro regeneration procedure (Fan et al. 2002; Fan et al. 2008). Of 
various factors influencing on Agrobacterium-mediated transformation and further in vitro regeneration of transgenic plant, it has been reported that ethylene inhibitors such as silver nitrate and aminoethoxyvinylglycine dramatically improve the transformation efficiency in several plant species (Chi and Pua 1989; Han et al. 2005; Sgamma et al. 2015). Hence, to ascertain the effect of the ethylene inhibitors on Agrobacterium -mediated transformation in grapevine 'Kyoho' become one of the goals of this study. Collectively, we here report an Agrobacterium-mediated genetic transformation system optimized for grapevine 'Kyoho' and the transformants with $D c A F P$ obtained as applying the improved system.

\section{Materials and Methods}

\section{Plant materials}

For isolation of carrot antifreeze protein gene $(D c A F P)$, seeds of carrot (Daucus carota cv. Socheon) (Asia Seed Company, Seoul, Korea) were germinated under a $16 / 8 \mathrm{~h}$ (day/night) at $27^{\circ} \mathrm{C}$. On the other hand, in vitro stock plants of grapevine (Vitis vinifera) 'Kyoho' were obtained via shoot tip culture using the methods by Kim et al. (2013) and Monette (1985). Briefly, the distal parts about $3 \mathrm{~cm}$ long were detached from rapidly growing shoots in the spring and surface-sterilized by submersion in 3.0\% sodium hypochlorite solution for 10 minutes, followed by rising them with sterile distilled water. Each shoot tip with several leaf primordia was excised after removing individual leaf scales, then placed on the MS medium (Murashige and Skoog 1962) with $1 \mathrm{mg} / \mathrm{L}$ BA (Sigma-Aldrich, USA), $30 \mathrm{~g} / \mathrm{L}$ sucrose (Duchefa Biochemie, The Netherlands), and $8 \mathrm{~g} / \mathrm{L}$ Plant Agar ${ }^{\mathrm{TM}}$ (Duchefa Biochemie). When the explants developed a shoot about 2 $\mathrm{cm}$ long and four to five well expanded leaves, they were transferred to the multiplication medium consisted of MS, $1 \mathrm{mg} / \mathrm{L} \mathrm{BA}, 0.1 \mathrm{mg} / \mathrm{L}$ IBA (Sigma-Aldrich), sucrose $30 \mathrm{~g} / \mathrm{L}$, $10 \mathrm{~g} / \mathrm{L}$ Plant Agar $^{\mathrm{TM}}$. Leaf discs from the multiplied shoots were excised and used as an explants for Agrobacteriummediated transformation experiments.
Construction of pBI121-DcAFP vector and bacterial strain

Total RNA was extracted from carrot leaves using the method for pine trees (Chang et al. 1993) with some modification: use of extraction buffer consisting of $2 \%$ cetyltrimethylammonium bromide, $2 \%$ polyvinylpyrrolidone, $100 \mathrm{mM}$ Tris- $\mathrm{HCl}$ (pH 8.0), $25 \mathrm{mM}$ ethylenediaminetetraacetic acid, $2 \mathrm{M} \mathrm{NaCl}, 0.05 \%$ spermidine, and $0.24 \%$ DTT. Reverse transcription was performed from $3 \mu \mathrm{g}$ of total RNA with oligo-dT by Moloney murine leukemia virus reverse transcriptase (Promega, Madison, W, USA). We designed a primer set to amplify DcAFP from the synthesized first strand cDNA: forward primer 5'-ACTCGAAAACATAATCCA-3' and reverse primer 5'-TGCACTGCTTGAGCTGCATA-3'. After PCR, the product was separated by electrophoresis in $1.5 \%$ agarose gel. Band of the expected size (approximately $1,099 \mathrm{bp}$ ) was excised from the gel and purified by using GENECLEAN turbo kit (MPbio). To create pBI121-DcAFP binary vector carrying the $C a M V 35 S$ promoter:DCAFP::NOS terminator and NOS promoter::nptII::NOS terminator cassettes (Fig. 1), the purified amplicon was combined with pBI121 vector (Genbank AF485783.1) after digesting its GUS gene as described previously (Wu et al. 2012). The recombined plasmid was introduced into Agrobacterium tumefaciens strain LBA 4404 by an electroporation, and the transformed Agrobacterium was selected and used for co-cultivation with grapevine leaf explants.

Ethylene inhibitor treatment during co-cultivation of explants with Agrobacterium

To observe the effect of ethylene inhibitors, ethylene action inhibitor silver nitrate $\left(\mathrm{AgNO}_{3}: 0.1,0.5,1.0,3.0 \mathrm{mg} / \mathrm{L}\right)$ and ethylene biosynthesis inhibitor aminoethoxyvinylglycine (AVG: $0.001,0.01,0.1,0.5 \mathrm{mg} / \mathrm{L}$ ) were additionally supplemented in a co-cultivation medium. Co-cultivation medium was consisted of MS inorganic salts, $0.1 \mathrm{~g} / \mathrm{L}$ myo-inositol, $0.8 \mathrm{mg} / \mathrm{L}$ thiamine- $\mathrm{HCl}, 30 \mathrm{~g} / \mathrm{L}$ sucrose, $0.1 \mathrm{mg} / \mathrm{L}$ IBA, 10 $\mathrm{mg} / \mathrm{L}$ acetosyringone (Sigma-Aldrich), $1 \mathrm{mM}$ proline (SigmaAldrich), and $8 \mathrm{~g} / \mathrm{L}$ Plant Agar $^{\mathrm{TM}}$, followed by adjusting $\mathrm{pH}$

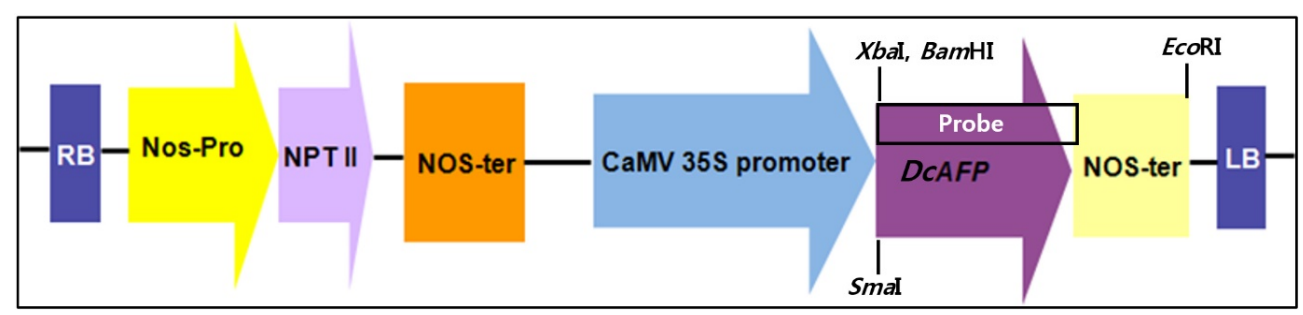

Fig. 1 Linear map of the T-DNA region of the recombinant pBI121-DcAFP showing the site of the inserted DcAFP. The EcoRI restriction site used for Southern blot analysis is shown above the map 
to 5.9 before autoclaving at $121^{\circ} \mathrm{C}$ for $20 \mathrm{~min}$. Culture flasks were sealed with rubber septum stoppers throughout cocultivation. After co-cultivation, the explants were transferred to a selection medium. For the selection medium, $5 \mathrm{mg} / \mathrm{L}$ thidizuron (TDZ; Sigma-Aldrich) and $200 \mathrm{mg} / \mathrm{L}$ Clavamox $^{\mathrm{TM}}$ (Pfizer, NY, USA) were supplemented in the co-cultivation medium, meanwhile acetosyringone, proline and ethylene inhibitors were removed from the co-cultivation medium. Regenerated shoots were observed five weeks after culturing on the selection medium.

\section{Decision of compromised antibiotics strength}

Four kinds of antibiotics (cefotaxime, carbenicillin, Clavamox ${ }^{\mathrm{TM}}$ and kanamycin) at various concentrations were added to the selection media to decide efficient antibiotics types and their concentrations for suppressing the development of nontransgenic shoot development but minimizing the inhibition of transgenic shoot regeneration (Table 2). Co-cultivation step was skipped for this experiment, and regenerated shoots were investigated.

\section{Agrobacterium-mediated transformation}

Agrobacterium cells were grown overnight at $28^{\circ} \mathrm{C}$ in the YEP medium containing $100 \mathrm{mg} / \mathrm{L}$ kanamycin on a rotary shaker $(250 \mathrm{rpm})$ till an $\mathrm{OD}=1.0$ at $550 \mathrm{~nm}$. Leaf explants were inoculated with the Agrobacterium culture for $10 \mathrm{~min}$ on a rotary shaker (150 rpm), and blotted dry on sterile filter paper. Inoculated explants were placed onto the co-cultivation medium with $0.1 \mathrm{mg} / \mathrm{L}$ AVG. The co-cultivation was carried out for 3 days at $27^{\circ} \mathrm{C}$ in the dark. Following co-cultivation, the explants were rinsed several times with the combination solution of $150 \mathrm{mg} / \mathrm{L}$ cefortaxime and $150 \mathrm{mg} / \mathrm{L}$ Clavamox ${ }^{\mathrm{TM}}$. Further cultivation of the explants was carried out on the selection medium containing $50 \mathrm{mg} / \mathrm{L}$ kanamycin. Regenerated shoots were detached from mother explants, and then transplanted on a rooting medium. Rooting medium was consisted of half strength MS, $30 \mathrm{~g} / \mathrm{L}$ sucrose, and $0.1 \mathrm{mg} / \mathrm{L}$ IBA. Rooted plantlets were transferred to plastic pot filled with commercial compost.

\section{Nucleic acid analyses}

Genomic DNA was extracted from young leaves using a modification of CTAB method (Torres et al. 1993). Approximately $100 \mathrm{mg}$ of fresh leaves was put into a pre-chilled mortar and grinded in liquid nitrogen. A $700 \mu \mathrm{L}$
CTAB buffer was added to the powder and the mixture was incubated at $65^{\circ} \mathrm{C}$ for $30 \mathrm{~min}$. After incubation, equal volume of phenol:chloroform:isoamylalcohol (25:24:1) was added and centrifuged at 13,000 rpm for $10 \mathrm{~min}$. The supernatant was transferred to a new tube, equal volume of chloroform: isoamylalcohol (24:1) was added and centrifuged at 13,000 rpm for $10 \mathrm{~min}$. The supernatant was transferred to a new tube, equal volume of isopropanol was added and centrifuged at $13,000 \mathrm{rpm}$ for $5 \mathrm{~min}$. The precipitated DNA was washed with $1 \mathrm{~mL}$ of $70 \%$ ethanol and dried for $1 \mathrm{~h}$. The DNA was dissolved in $100 \mu \mathrm{L}$ of sterile $\mathrm{H}_{2} \mathrm{O}$ with $2 \mu \mathrm{L}$ of RNase A and incubated at $37^{\circ} \mathrm{C}$ for $1 \mathrm{~h}$. After determination of DNA concentration and purity, the extracted total DNA was stored at $-20^{\circ} \mathrm{C}$.

Detection of integrated transgenes was performed by PCR and Southern blot analyses (Southern 1975). Primer sets for PCR analysis were designed to amplify DcAFP and nptII fragments: primer set for DcAFP mentioned above, and forward primer for $n p t I I, 5$ '-ATACTTTCTCGGCAGG AGCA-3' and reverse primer for $n p t I I$, 5'-ACAAGCCGT TTTACGTTTGG-3'. Southern blot analysis was also performed to confirm stable integration of the DcAFP. Briefly, a ten $\mu \mathrm{g}$ of genomic DNA was digested with the restriction enzyme EcoRI. Following gel electrophoresis, separated DNA fragments were transferred to Hybond $\mathrm{N}$ nylon membrane and hybridized to a PCR-generated DIG-labeled probe. Hybridization was carried out at $68^{\circ} \mathrm{C}$ for $16 \mathrm{~h}$. DIG Easy Hyb, DIG Wash/Block Buffer set and CDP-Star Ready to Use (Roche) were used for hybridization, washing and detection, respectively. Detected blots were exposed to X-ray films (Amersham Bioscience). In addition, total RNAs were extracted from the newly developing leaves of the plants using Plant RNeasy Mini kit (QIAGEN, USA). First-strand cDNAs were synthesized from $1 \mu \mathrm{g}$ of total RNA with random hexamers using SuperScript III First-strand cDNA Synthesis Kit (Invitrogen, USA) according to the manufacturer's instructions. The primer set mentioned above for detection of DcAFP was used again for its cDNA amplification.

\section{Results and Discussion}

Creation of recombinant $\mathrm{pBI} 121-D c A F P$ vector

A fragment of about 1,099 bp in length was amplified from the cDNA of carrot by RT-PCR, which was recombined into pBI121 binary vector, resulting in creation of pBI121$D c A F P$ (Fig. 1). 
Increase of shoot regeneration efficiency by using ethylene inhibitors in co-cultivation medium

Wounded plant tissues are able to produce significant amounts of ethylene during in vitro culture (Beyer 1979; Pua 1993). Besides wound ethylene obstructs adventitious shoot regeneration from explants, the production of this gaseous phytohormone is promoted by Agrobacterium inoculation, resulting in a reduction in the efficiency of foreign gene transfer (Ezura et al. 2000; Han et al. 2004; Han et al. 2005; Nonaka et al. 2008). To ascertain the beneficial effects of $\mathrm{AgNO}_{3}$ and $\mathrm{AVG}$ in grapevine transformation, $0.001 \sim 0.5 \mathrm{mg} / \mathrm{L} \mathrm{AVG}$ or $0.1 \sim$ $3.0 \mathrm{mg} / \mathrm{L} \mathrm{AgNO}_{3}$ were supplemented in the co-cultivation medium. The application of $0.1 \mathrm{mg} / \mathrm{L}$ AVG or $\mathrm{AgNO}_{3}$ increased the regeneration frequency by $5 \%$ or $4.3 \%$, respectively (Table 1). It has been known that wound ethylene production varies among species, genotypes and tissue types (Ezura et al. 2000). Our result implies that ethylene inhibitors such as AVG and $\mathrm{AgNO}_{3}$ at Agrobacterium co-cultivation step can facilitate regeneration of putative transgenic shoots in grapevine as well, although we did not verify whether the regenerated shoots were transgenic or not. Thus, $0.1 \mathrm{mg} / \mathrm{L}$ AVG was added in the co-cultivation media during the following experiments.

For this experiment, $50 \mathrm{mg} / \mathrm{L}$ kanamycin and $200 \mathrm{mg} / \mathrm{L}$ Clavamox $^{\mathrm{TM}}$ were also supplied in the selection medium. The data represent the mean values nine replicates. Values followed by the same letter within the last column are not

Table 1 Effects of ethylene inhibitors in co-cultivation medium on shoot regeneration from 'Kyoho' leaf explants sub-cultured in selection medium

\begin{tabular}{ccc}
\hline $\begin{array}{l}\text { Ethylene inhibitor }(\mathrm{mg} / \mathrm{L}) \\
\text { in co-cultivation medium }\end{array}$ & $\begin{array}{c}\text { Shoot regeneration (\%) } \\
\text { in selection medium }\end{array}$ \\
\hline AVG & 0.0 & $0.5 \mathrm{~d}$ \\
& 0.001 & $2.9 \mathrm{c}$ \\
& 0.01 & $3.3 \mathrm{c}$ \\
& 0.1 & $5.0 \mathrm{a}$ \\
& 0.5 & $4.1 \mathrm{~b}$ \\
& & \\
$\mathrm{AgNO}_{3}$ & 0.1 & $4.3 \mathrm{~b}$ \\
& 0.5 & $3.2 \mathrm{c}$ \\
& 1.0 & $3.0 \mathrm{c}$ \\
& 3.0 & $3.3 \mathrm{c}$
\end{tabular}

For this experiment, $50 \mathrm{mg} / \mathrm{L}$ kanamycin and $200 \mathrm{mg} / \mathrm{L} \mathrm{Clavamox}^{\mathrm{TM}}$ were also supplied in the selection medium. The data represent mean values of 9 replicates. Values followed by the same letter within the last column are not significantly different according to Duncan's multiple range test at the $5 \%$ level significantly different according to Ducan's multiple range test at the $5 \%$ level.

Effects of antibiotics on shoot regeneration

In almost Agrobacterium-mediated transformation trials, antibiotics such as carbenicillin, cefotaxime and Clavamox ${ }^{\mathrm{TM}}$ are widely used to eliminate bacterial cells that have completed their mission (Alsheikh et al. 2002; Mathias and Boyd 1986). Kanamycin is also applied for selecting out any non-transgenic regenerants if nptII is inserted into T-DNA as a selectable marker gene. However, plant regeneration can be disturbed by the antibiotics, especially severely at high concentration (Holford and Newbury 1992; Ling et al. 1998). We tested various antibiotics for application in the subsequent $D c A F P$ transformation experiments. The higher concentrations of the antibiotics tendentially showed lower regeneration efficiency, while kanamycin that is the selectable antibiotics in current study drastically suppressed shoot regeneration despite the low concentrations at $25 \mathrm{mg} / \mathrm{L}$ or $50 \mathrm{mg} / \mathrm{L}$ (Table 2). As results, we chose $150 \mathrm{mg} / \mathrm{L}$ cefotaxime plus $150 \mathrm{mg} / \mathrm{L}$ Clavamox ${ }^{\mathrm{TM}}$ as the compromised condition for controlling feasible Agrobacterium over-growth in a selection medium and $50 \mathrm{mg} / \mathrm{L}$ kanamycin as the concentration for suppressing the regeneration of non-transgenic shoots.

The data represent the mean values six replicates. Values followed by the same letter within the last column are not significantly different according to Ducan's multiple range test at the $5 \%$ level.

Table 2 Effects of antibiotics on shoot regeneration from leaf explants in grapevine 'Kyoho'

\begin{tabular}{lcc}
\hline \multicolumn{1}{c}{ Antibiotics $(\mathrm{mg} / \mathrm{L})$} & Shoot regeneration $(\%)$ \\
\hline \multirow{3}{*}{ Cefotaxime } & 0 & $30.9 \mathrm{a}$ \\
& 150 & $26.7 \mathrm{~b}$ \\
Carbenicillin & 250 & $16.4 \mathrm{c}$ \\
& 300 & $25.8 \mathrm{~b}$ \\
Clavamox $^{\mathrm{TM}}$ & 500 & $18.5 \mathrm{c}$ \\
& 100 & $20.7 \mathrm{bc}$ \\
Cefotaxime/Clavamox $^{\mathrm{TM}}$ & $100 / 100$ & $17.5 \mathrm{c}$ \\
& $150 / 150$ & $18.9 \mathrm{c}$ \\
Kanamycin $^{*}$ & 200 & $8.4 \mathrm{~d}$ \\
& 50 & $2.0 \mathrm{e}$ \\
\hline
\end{tabular}

The data represent mean values of 6 replicates. Values followed by the same letter within the last column are not significantly different according to Duncan's multiple range test at the $5 \%$ level 

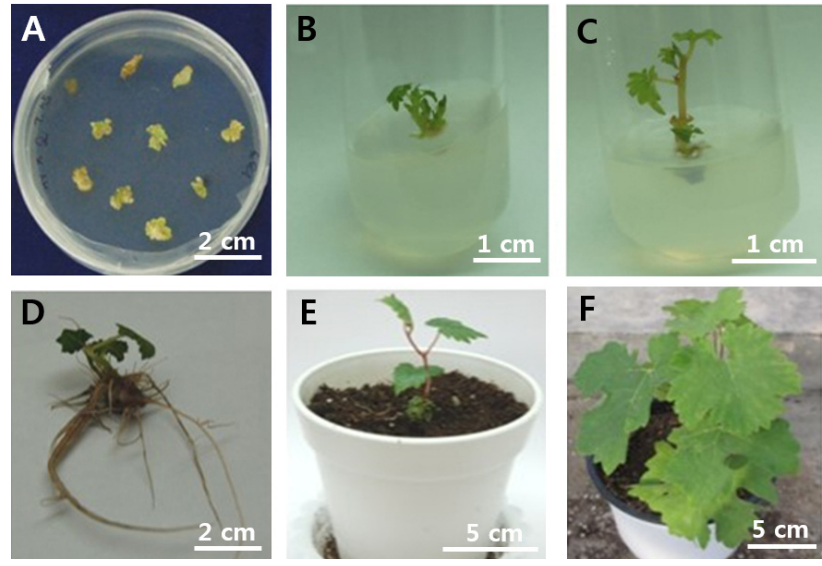

Fig. 2 Exhibition on generation of DcAFP-transformant in grapevine 'Kyoho'. A: Induction of putative transgenic shoot from leaf explants on a selection medium, B-C: Detached and subsequently sub-cultured shoot on a rooting medium, D: Plantlet with vigorous roots just before transplanting to a pot, E-F: Acclimatization and growth of the plantlets ex vitro

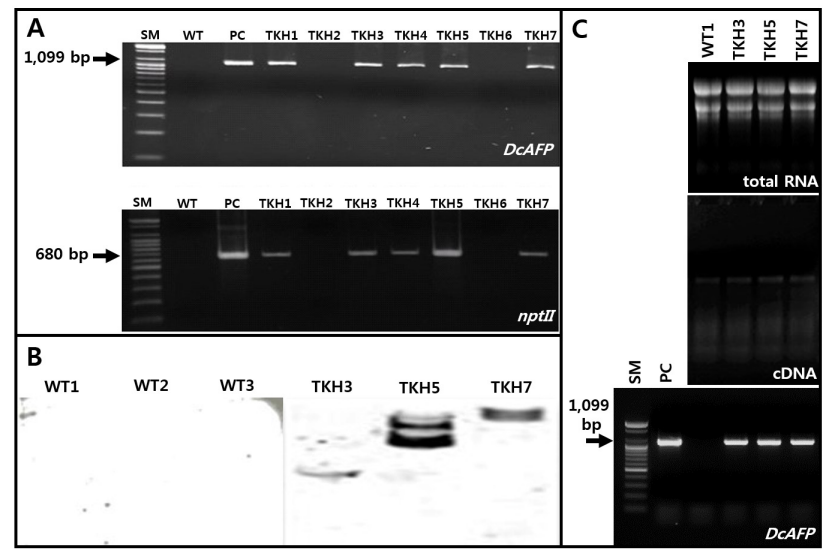

Fig. 3 Detection of transgenes and transcript of DcAFP through PCR, Southern blot, and RT-PCR analyses. A: PCR analysis of 7 acclimatized plantlets, B: Southern blot analysis for DcAFP of randomly selected three PCR-positive plantlets, C: RT-PCR analysis for detecting transcript of DcAFP, SM: $100 \mathrm{bp}$ size marker, WT1-WT3: wild type plants, PC: positive control (plasmid DNA), TKH1-TKH7: putative transgenic plantlets

\section{Generation of $D c A F P$-expressing plants}

With five batches of DcAFP transformation experiment, a thousand of leaf explants were co-cultivated with the Agrobacterium in the medium with $0.1 \mathrm{mg} / \mathrm{L}$ AVG and then transferred on the selection medium with antibiotics. Sixteen adventitious shoots with a little bit of calli were regenerated (approximately 1.6\%) on the selection medium (Fig. 2A). When the detached shoots were transplanted onto a rooting medium, all of sixteen shoots vigorously rooted (Fig. 2B-D). However, nine plantlets failed in ex vitro acclimatization while seven successfully adapted to a greenhouse condition (Fig. 2E-F). This result also implies that the acclimatization is an important step for grapevine in terms of transformation efficiency.

Completely acclimatized plantlets were subjected to PCR, Southern blot, and RT-PCR analyses to detect the transgenes and the transcript of DcAFP. Among the seven plantlets, five plantlets contained DcAFP and nptII at the size of 1,099 bp and $680 \mathrm{bp}$, respectively (Fig. 3A). This result shows that the transformation efficiency of current study based on the PCR result was about $0.5 \%$. Southern blot analysis also showed the DCAFP insertion into the 'Kyoho' genome and the number of T-DNA copy ranging from one to four (Fig. 3B). In addition, the result of RT-PCR analysis indicated that the DcAFP gene(s) in each transgenic plant transcribes normally.

Together, we generated transgenic grapevine 'Kyoho' plants with carrot antifreeze protein gene $(D c A F P)$ as simultaneously improving Agrobacterium-mediated transformation procedure, especially as applying ethylene inhibitors and compromised selection pressure. The final transgenic products are going to be tested for cold tolerance after vegetative propagation. In addition to current study, we are making to effort for enhancing the cold tolerance of a rootstock that is an important factor in grapevine cultivation.

\section{References}

Alsheikh MK, Suso HP, Robson M, Battey NH, Wetten A (2002). Appropriate choice of antibiotic and Agrobacterium strain improves transformation of antibiotic-sensitive Fragaria vesca and Fragaria vesca semperflorens. Plant Cell Rep 20:1173-1180

Beyer EM (1979) Effect of silver ion, carbon dioxide and oxygen on ethylene action and metabolism. Plant Physiol 63:169-173

Chang S, Puryear J, Cairney J (1993) A simple and efficient method for isolating RNA from pine trees. Plant Mol Biol Rep 11:113-116

Chi G-L, Pua E-C (1989) Ethylene inhibitors enhanced de novo shoot regeneration from cotyledons of Brassica campestris ssp. chinensis (Chinese cabbage) in vitro. Plant Sci 64:243-250

DeVries AL, Komatsu SK, Feeney RE (1970) Chemical and physical properties of freezing point-depressing glycoproteins from Antarctic fishes. J Biol Chem 245:2901-2908

Ezura H, Yuhashi KI, Yasuta T, Minamisawa K (2000). Effect of ethylene on Agrobacterium tumefaciens-mediated gene transfer to melon. Plant Breed 119:75-79

Fan C, Pu N, Wang X, Wang Y, Fang L, Xu W, Zhang (2008). Agrobacterium-mediated genetic transformation of grapevine (Vitis vinifera L.) with a novel stilbene synthase gene from Chinese wild Vitis pseudoreticulata. Plant Cell Tiss Org Cult 92:197-206

Fan Y, Liu B, Wang H, Wang S, Wang J (2002). Cloning of an 
antifreeze protein gene from carrot and its influence on cold tolerance in transgenic tobacco plants. Plant Cell Rep 21: 296-301

Han JS, Kim CK, Park SH, Hirschi KD, Mok IG (2005) Agrobacterium-mediated transformation of bottle gourd (Lagenaria siceraria Standl.). Plant Cell Rep 23:692-698

Han JS, Oh DG, Mok IG, Park HG, Kim CK (2004) Efficient plant regeneration from cotyledon explants of bottle gourd (Lagenaria siceraria Standl.). Plant Cell Rep 23:291-296

Holford P, Newbury HJ (1992) The effects of antibiotics and their breakdown products on the in vitro growth of Antirrhinum majus. Plant Cell Rep 11:93-96

Iocco P, Franks T, Thomas MR (2001). Genetic transformation of major wine grape cultivars of Vitis vinifera $\mathrm{L}$. Transgenic Res 10:105-112

Jang Y, Jia SR, Fei YB, Tan KH (1999) Antifreeze proteins and their role in plant antifreeze physiology (in Chinese). Acta Bot Sin 41:677-685

Jin W, Dong J, Hu Y, Lin Z, Xu X, Han Z (2009) Improved cold-resistant performance in transgenic grape (Vitis vinifera L.) overexpressing cold-inducible transcription factors AtDREB1b. HortScience 44:35-39

Kim SH, Shin IS, Cho KH, Kim DH, Kim HR, Kim JH, Lim S-H, Kim KO, Lee HB, Do KR, Hwang HS (2013) Plant regeneration and transformation of grape (Vitis labrusca L.) via direct regeneration method. J Plant Biotechnol 40:210-216

Li ZT, Dhekney S, Dutt M, van Aman M, Tattersall J, Kelly KT, Gray DJ (2006) Optimizing Agrobacterium-mediated transformation of grapevine. In Vitro Cell Dev Biol-Plant 42:220-227

Ling HQ, Kriseleit D, Ganal MW (1998) Effect of ticarcilline/ potassium clavulanate on callus growth and shoot regeneration in Agrobacterium-mediated transformation of tomato (Lycopersicon esculentum Mill.). Plant Cell Rep 17:843-847

Mathias RJ, Boyd LA (1986) Cefotaxime stimulates callus growth, embryogenesis and regeneration in hexaploid bread wheat (Triticum aestivum $\mathrm{L}$ em. thell). Plant Sci 46:217-223

Meyer K, Keil M, Naldrett MJ (1999). A leucine-rich repeat protein of carrot that exhibits antifreeze activity. FEBS Lett 447:171-178

Monette PL (1985) Use of grapevine shoot tip cultures for detection of Fanleaf virus by enzyme-linked immunosorbent assay. Can J Plant Sci 65:977-980

Murashige T, Skoog F (1962) A revised medium for rapid growth and bioassay with tobacco tissue cultures. Physiol Plant 15:473-497

Nonaka S, Yuhashi K-I, Takada K, Sugaware M, Minamisawa K, Ezura H (2008) Ethylene production in plants during transformation suppresses vir gene expression in Agrobacterium tumefaciens. New Phytol 178:647-656

Pua EC (1993) Cellular and molecular aspects of ethylene on plant morphogenesis of recalcitrant Brassica species in vitro. Bot Bull Acad Sin 34:191-209

Sgamma T, Thomas B, Muleo R (2015) Ethylene inhibitor silver nitrate enhances regeneration and genetic transformation of Prunus avium (L.) cv Stella. Plant Cell Tiss Organ Cult 120:79-88

Southern EM (1975) Detection of specific sequences among DNA fragments separated by gel electrophoresis. J Mol Biol 98:503-517

Sun L, Song W, Geng Q, Du YP, Zhai H, Qin W (2016) Comparison of cold hardiness in the leaves of various grape cultivars based on photochemical reflectance index. Vitis 55:107-112

Torregrosa L, Vialet S, Adivèze A, Iocco-Corena P, Thomas MR (2015) Grapevine (Vitis vinifera L.). Methods Mol Biol 1224:177-194

Torres AM, Weeden NF, Martin A (1993). Linkage among isozyme, RFLP and RAPD markers in Vincia faba. Theor Appl Genet 85:937-945

Wang L, Nick P (2017) Cold sensing in grapevine - Which signals are upstream of the microtubular "thermometer". Plant Cell Environ 2017:1-14

Worrall D, Elias L, Ashford D, Smallwood M, Sidebottom C, Lillford P, Telford J, Holt C, Bowles D (1998) A carrot leucine-rich-repeat protein that inhibits ice recrystallization. Science 282:115-117

Wu Q, Lin J, Liu JZ, Wang X, Lim W, Oh M, Park J, Rajashekar CB, Whitham SA, Cheng NH, Hirschi KD, Park S (2012) Ectopic expression of Arabidopsis glutaredoxin AtGRXS17 enhances thermotolerance in tomato. Plant Biotechnol J 10:945-955 